\title{
PRAKTIKUM ALGORITMA DAN PEMOGRAMAN BERORIENTASI OBJEK UNTUK PEMULA DENGAN DUKUNGAN PEMOGRAMAN VISUAL DINAMIS
}

\author{
Kursehi Falgenti ${ }^{1}$, Rahmatika ${ }^{2}$ \\ Program Studi Informatika Universitas Indrprasta PGRI \\ Jl. Raya Tengah No.80 Kel. Gedong Kec. Pasar Rebo, Jakarta Timur \\ ${ }^{1}$ kursehi_falgenti@unindra.ac.id \\ ${ }^{2}$ rahmanasrul@gmail.com
}

\begin{abstract}
ABSTRAK
Mata kuliah Algoritma Pemograman merupakan matakuliah wajib di fakultas Ilmu Komputer. Dalam matakuliah ini mahasiswa mempelajari pemograman paradigma berorientasi prosedur kemudian dilanjutkan dengan paradigma berorientasi objek. Paradigma beroreintasi objek lebih sulit dipelajari karena pembahasan pemrograman berorientasi objek ini sangat luas, Menurut beberapa peneliti, siswa di negara berkembang menganggap pelajaran algoritma dan pemrograman sulit dipelajari. Untuk memudahkan mahasiswa menerima materi algoritma dan pemograman berorientasi objek peneliti telah mengembangkan pemrograman visual, konsep belajar yang memvisualisasikan proses kerja algoritma dan pemograman. Penelitian ini bertujuan menganalisa dan mempelajari tiga tool pemrograman visual dinamis. Metode yang digunakan dalam menganalisa adalah metode survei artikel-artikel penelitian tentang pemrograman visual. Dari hasil survei, dipilih tiga tool pemrograman visual yang banyak dipublikasikan, yaitu Jeliot, Ville, dan Jive. Hasil penelitian menunjukkan bahwa Ville memiliki beberapa keunggulan di antara tool pemrograman visual. Keunggulan tersebut di antaranya: tersedia materi untuk praktikum dan Ville bisa digunakan untuk banyak bahasa pemrograman berorientasi objek, tidak hanya bahasa pemrograman Java. Ville lebih cocok digunakan untuk mendukung praktikum algoritma dan pemrograman berorientasi objek di negeri berkembang seperti Indonesia bila tersedia interface dalam Bahasa Indonesia.
\end{abstract}

Kata Kunci: Praktikum pemrograman, pemrograman visual, pemrograman berorientasi objek.

\section{A. PENDAHULUAN}

Pemrograman adalah topik utama yang selalu diajarkan kepada mahasiswa di Fakultas Ilmu Komputer. Tahun pertama kuliah, mereka mendapatkan mata kuliah pengenalan algoritma dan pemrograman. Ketika mempelajari pengenalan algoritma dan pemrograman, mahasiswa mempelajari banyak istilah. Istilah dalam pemrograman berorientasi objek akan lebih sulit dipelajari bila mahasiswa tidak memahami pemrograman berorientasi prosedur dengan baik (Thramboulidis, 2013). Pada pemrograman berorientasi objek, aliran kontrol dan fungsinya yang terdistribusi lebih sulit dipahami dibandingkan dengan pemograman prosedural, sehingga bagi pemula sulit membentuk representasi mental aliran kontrol dan fungsi pada pemrograman berorientasi objek (Wiedenbeck et al., 1999: 276). Selain itu, Wiedenbeck et al. (1999: 277) menyatakan para pemula lebih lama memahami program berorientasi objek sebagian disebabkan oleh kurva pembelajaran berorientasi objek yang lebih panjang dan sebagian lagi karakter program berorientasi objek yang lebih luas pembahasanya.

Sebagai pemula, mahasiswa dapat dengan mudah memahami bagaimana komputer bekerja namun mahasiswa kesulitan memahami bagaimana sebuah program bekerja dari kode program yang ditulis, penyebabnya menurut Levy et al. (2003), mahasiswa kesulitan membangun mind map. Ketika mempelajari dasar program, mahasiswa sebagai pemula belajar banyak istilah yang berbeda, pada pemrograman berorientasi objek lebih banyak istilah baru. Mempelajari istilah baru membingungkan pemula (Ben-Ari et al., 2002). Mereka juga kurang memilki kemampuan dalam tugas-tugas dasar seperti memahami eksekusi program. Selain itu juga bermasalah dengan perencanaan dan penerapan 
algoritma.

Paradigma beroreintasi prosedur dan paradigma berorientasi objek merupakan dua pendekatan yang diajarkan kepada pemula dalam pembelajaran pemrograman. Kedua paradigma memilki karakter yang berbeda. Pemrograman berorientasi objek lebih sulit dipelajari karena banyak istilah baru yang jauh berbeda dengan istilah pada pemrograman berorientasi prosedur. Materi yang harus dipelajari untuk memahami pemrograman berorientasi objek lebih banyak, sehingga membutuhkan waktu yang lama untuk mempelajarinya.

Java adalah salah satu bahasa pemrograman beroreintasi objek yang paling banyak digunakan di kampus (Pears et al., 2007). Java banyak digunakan karena tool pembelajaran yang bersifat free. Komunitas pengajar pemograman menggunakan Java secara luas dan mereka mendapatkan keuntungan dari pengembangan dan penelitian sebagai alat dan teknik pedagogi.

Agar pembelajaran pemrograman berorientasi objek menggunakan Java lebih efektif peneliti mengembangkan metode pengajaran dengan dukungan pemrograman visual dalam penyampaian materi. Banyak tool pemrograman visual yang telah dibuat dengan tujuan yang berbeda. Ada yang hanya fokus untuk memvisualisasikan algoritma ada juga yang juga berfungsi sebagai tool untuk memvisualisasikan pemrograman.

Beberapa peneliti mengembangkan tool untuk pembelajaran pengenalan pemrograman menggunakan pemrograman visual (visual programming). Pemrograman visual dikembangkan menjadi pemrogramam visual dinamis. Beberapa tool pemrograman visual yang telah dibuat untuk mendukung pembelajaran pemrograman beroreintasi objek di antaranya adalah BlueJ (Kolling \& Rosenberg, 2000, 2001; Kölling et al., 2003), Jeliot (Levy et al., 2003), JIVE (Gestwicki \& Jayaraman, 2002) and VILLE (Rajala et al., 2007).

Tool untuk pembelajaran pemrograman visual ini dikembangkan dan telah digunakan di negara maju. Pendekatan pembelajaran pengenalan pemrograman berorientasi objek menggunakan pemrograman visual dinamis ini perlu diadopsi di negara berkembang. Karakteristik mahasiswa di negara maju sangat berbeda di negara berkembang. Menurut Apiola and Tedre (2012), dalam pelajaran pemrograman mahasiswa-mahasiswa di negara berkembang memiliki kemampuan belajar yang rendah sehingga mereka memiliki pengetahuan pemrograman yang dangkal. Karena itu perlu usaha kreatif untuk meningkatkan keterampilan dan pengetahuan pemrograman siswa di negara berkembang. Salah satu usah kreatif tersebut adalah menggunakan pemrograman visual sebagai tool pendukung dalam mata kuliah algoritma dan pemrograman, khusunya dalam pelaksanaan praktikum.

Penelitian ini bertujuan melakukan analisa terhadap tiga tool pemograman visual, yaitu JELIOT 3, VILLE, dan JIVE, untuk mendukung praktikum pembelajaran pemograman berorientasi objek pada mahasiswa pemula agar dapat berjalan lebih efektif. Dengan penerapan pemrograman visual diharapkan dapat membantu dosen menyampaikan materi praktikum pelajaran pemrograman lebih efektif. Interaksi antara dosen dan mahasiswa diharapkan dapat lebih ekspresif. Mahasiswa dapat menyerap materi praktikum di bidang pemrograman berorientasi objek dengan lebih baik sehingga dapat meningkatkan proses pembelajaran.

\section{B. METODE PENELITIAN}

Penelitian ini merupakan penelitian analisis dekriptif, menganalisa artikel penelitian dengan topik pemrograman visual. Dari 45 artikel yang dianalisa, ditemukan tiga tool yang paling banyak dibahas, tool terebut adalah Jeliot, Ville, dan Jive. Selanjutnya, tool tersebut digunakan untuk melihat keunggulan masing-masing. Berdasarkan hasil tes dan analisa 
artikel, dapat direkomenasikan tool yang dapat digunakan untuk mendukung praktikum algoritma pemrograman berorientasi objek untuk pemula di negara berkembang.

\section{HASIL DAN PEMBAHASAN}

\section{JELIOT 3}

Jeliot telah melewati banyak tahap perkembangan, mulai dari sistem pendahulunya Eliot dan terus dikembangkan menjadi Jeliot I, Jeliot 2000, dan versi terbaru Jeliot 3. Versi terakhir Jeliot 3 diimplementasikan di Universitas Joensuu oleh Niko Myller dan Andre's Moreno di bawah supervisi dari Mordechai Ben-Ari dan Erkki Sutinen. Eliot and Jeliot I lebih mirip seperti algorithm visualization, sedangkan Jeliot 2000 (Levy et al., 2003) and Jeliot 3 lebih dekat dengan pemrograman visual.

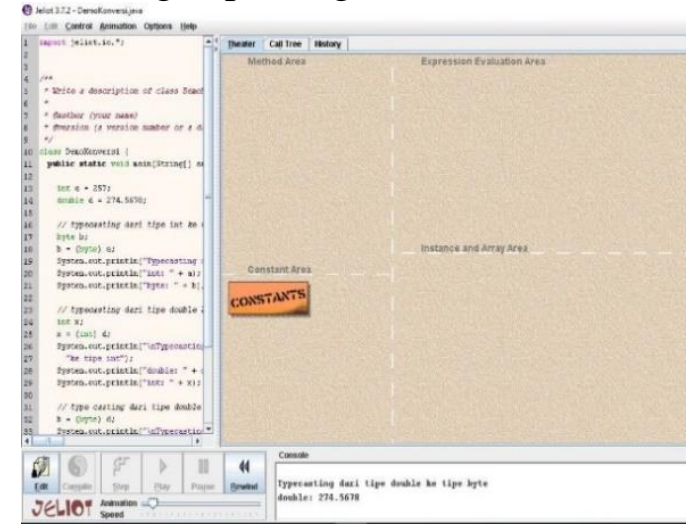

Gambar 1. Tampilan Jeliot 3

Bagian kiri pada gambar 1 merupakan list program, sementara di tengah terdiri dari empat bagian, yaitu method area, expression evaluation area, constanta area dan instance and array area. Masing-masing area akan aktif memvisualisasikan apa saja yang terjadi saat program dieksekusi, sedangkan bagian kanan bawah merupakan console yang menampilkan output program

\section{VILLE}

Ville dikembangkan oleh Teemu Rajala, Mikko-Jussi Laakso, Erkki Kaila, dan Tapio Salakoski dari University of Turku, Turku, Finlandia. Berbeda dengan tool pemrograman visual lainnya yang hanya bisa mengunakan Java, Ville dibangun dari syntax editor, dengan pendekatan ini pengguna bisa menambahkan bahasa baru ke dalam tool VILLE. Sampai saat ini, Ville bisa digunakan untuk bahasa berorientasi objek seperti Java, C++, Pyton, PHP, dan bahasa Pseudo. 


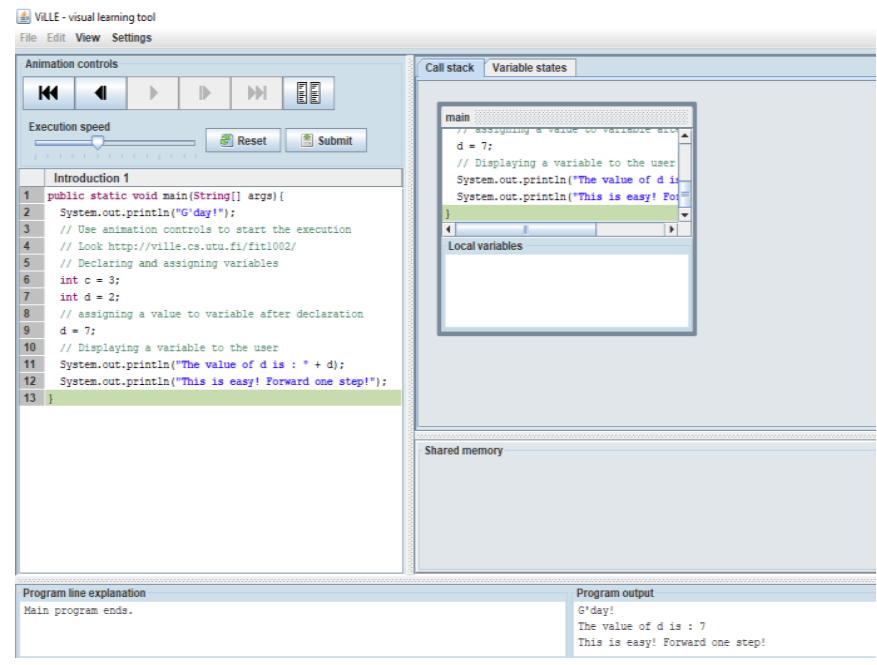

Gambar 2. Tampilan Ville

Bagian kanan atas pada gambar 2 merupakan pengatur animasi, di bawahnya adalah listing program. Bagian paling kiri bawah merupakan pejelasan line program yang sedang dieksekusi. Pada bagian kanan atas merupakan call stack yang menandai bagian line program yg dieksekusi. Kotak di bawahnya menujukkan variabel lokal yang sedang digunakan. Di pojok kanan bawah merupakan output program.

\section{JIVE}

JIVE dikembangkan oleh Paul Gestwicki, Bharat Jayaraman dari Department of Computer Science and Engineering, University at Buffalo Amerika. JIVE merupakan pendekatan baru untuk memvisualisasikan keadaan eksekusi program berorientasi objek, khususnya Java. Jive dirancang sebagai alat eksekusi visual interaktif untuk Java. Hal ini memungkinkan eksekusi interaktif dari program pengguna, memberikan tampilan grafis dari keadaan eksekusi dengan cara yang jelas. Tampilan Jive ada dua jenis, yaitu objek diagram view dan sequence diagram. Ville merupakan plug in dari IDE eclipse. Jive dipasang sebagai tool pendukung pada IDE Ecipse.
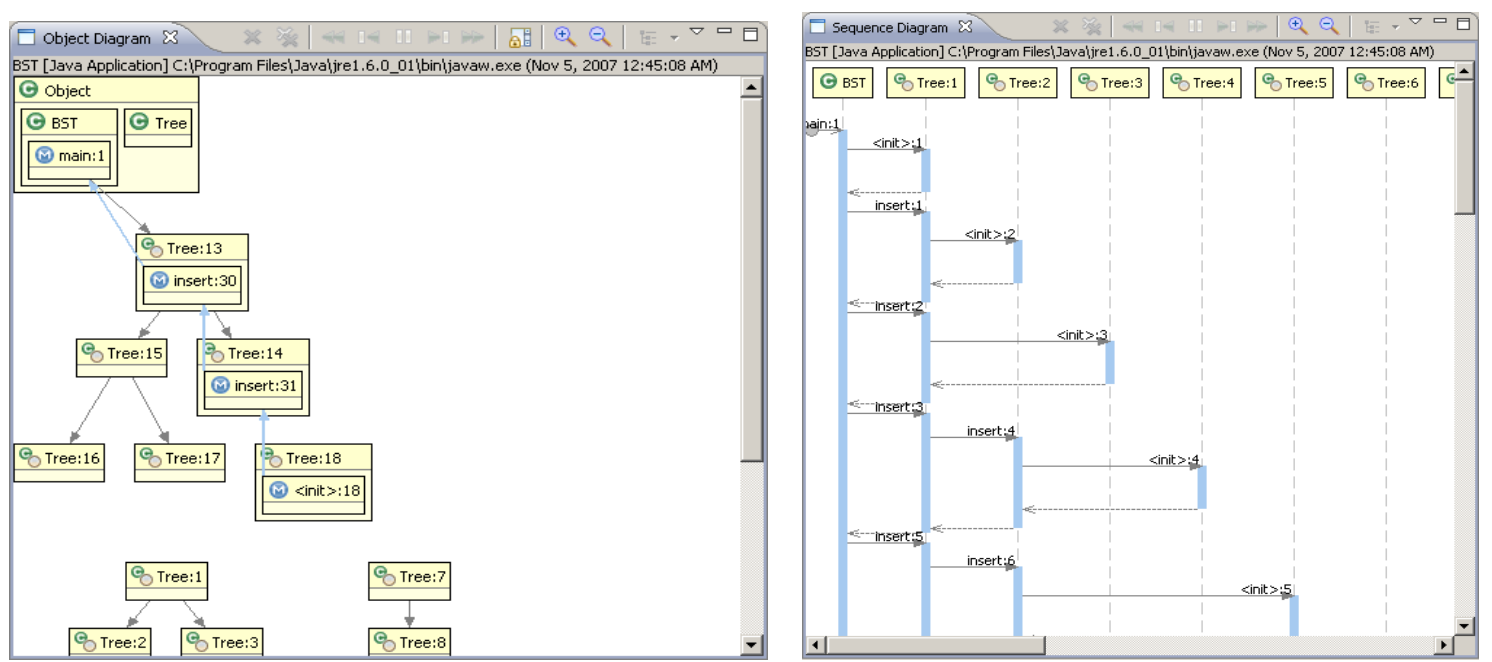

Gambar 3. Tampilan Jive (Objek Diagram dan Sequence diagram) 
Pada gambar 3, Jive menampilkan objek-objek yang aktif saat program dieksekusi, selain itu juga menampilkan diagram yang merepresentasikan referensi objek. Aktivasi method juga muncul dalam diagram pada objek yang sesuai atau konteks statis. Koneksi berwarna antara aktivasi method mewakili tautan kembali. Setiap thread diberi warna sendiri.

Pada gambar 4 dapat dilihat sequence diagram yang menggambarkan eksekusi suatu program. Objek dan konteks statis tercantum di bagian atas diagram. Aktivasi method muncul sebagai persegi panjang yang tumbuh secara vertikal yang ditempatkan di bawah objek atau konteks pelaksanaan statis. Seperti halnya diagram objek, setiap thread diberi warna sendiri. Koneksi solid dalam diagram mewakili pemanggilan method, dan koneksi putus-putus merepresentasikan pengembalian method.

Selain tiga tool di atas, banyak juga yang menggunakan BlueJ. BlueJ dirancang dan dikembangkan utuk tujuan pendidikan. BlueJ dikembangkan tahun 1999 oleh Michael Kölling and John Rosenberg dari Universitas Monash. Bulan Maret 2009, proyek BlueJ menjadi free dan menjadi software open source di bawah lisensi GNU GPL dengan pengecualian pada classpath exception. Sayangnya, BlueJ adalah tool pemrograman visual yang bersifat statis, sedangkan Jeliot, JIVE dan VILLE adalah tool pemograman visual yang bersifat dinamis. Pemograman visual statis tidak memvisualisasikan pelaksanaan program secara bertahap, tetapi fokus pada pemformatan struktur program dan hubungan antara komponen program. BlueJ memiliki tampilan kelas yang menunjukkan hubungan antara kelas dan objek yang berisi semua objek yang diinisialisasi, sedangkan VILLE, Jeliot 3 dan JIVE memiliki tujuan dasar dan beberapa fitur yang sama. Namun, perbedaan ada pada tingkat abstraksi dari visualisasi. Ketiga tool pemrograman visual dinamis ini dirancang untuk pengajaran bahasa pemrograman berorientasi objek untuk pemula.

Studi tentang penerapan pemrograman visual dalam proses belajar mengajar sudah banyak dilakukan di kampus-kampus negara maju, seperti studi Boyle et al. (2003) menyatakan pendekatan grafik dalam pengenalan pemrograman berperan terhadap mahasiswa dalam transisi kurikulum di London Metropolitan University. Studi Kannusmäki et al. (2004) mengevaluasi penggunaan Jeliot 3 di Universitas Joensuu Finlandia, hasil studi menunjukkan Jeliot 3 meningkatkan kemampuan para pemula untuk memahami pernyataan if else dan loop, memahami objek, dan menelusuri kesalahan dari kode program. Studi untuk melihat efektivitas penggunaan pemrograman visual dinamis Ville di Universitas Turku, Finlandia dilakukan oleh Rajala et al. (2008). Dari hasil studinya Rajala et al. (2008) menyimpulkan pemrograman visual dapat meningkatkan pembelajaran siswa. Studi oleh Sorva et al. (2013) menunjukkan pemograman visual memberi dapak positif terhadap pembelajaran pengenalan program.

\section{SIMPULAN DAN SARAN}

Berdasarkan fungsinya, semua tool pemrograman visual yag telah dibahas memiliki kemampuan visualisasi yang hampir sama, yang membedakan adalah kemampuan memvisualkan jenis bahasa pemrograman berorientasi objek yang berbeda. Ville memiki keunggulan dalam menampilkan eksekusi program yang ditulis dengan bahas Java, C++, Pyton, PHP, dan bahasa Pseudo, sedangkan Jeliot dan Jive hanya mampu menampilkan eksekusi program yang ditulis dengan bahasa Java.

Kenggulan Ville dibandingkan dengan pemrograman visual yang lain adalah adanya materi pemrograman berorientasi objek dalam aplikasi, berupa list program sederhana yang dapat digunakan untuk praktikum algoritma dan pemograman berorientasi objek. Instruktur juga dapat menambahan materi praktikum yang mereka anggap penting ke dalam aplikasi. 
Dari tiga tool pemograman isual yang dibahas tidak ada satupun tool yang menyediakan interface dalam bahasa Indonesia, kemampuan bahasa Inggris yang kurang terutama di negara berkembang akan menghambat proses belajar mengajar atau praktikum pemrograman berorientasi objek. Untuk negara berkembang seperti Indonesia, perlu dibuat interface dengan dukungan bahasa Indonesia.

\section{DAFTAR PUSTAKA}

Apiola, M. dan Tedre, M. (2012). New perspectives on the pedagogy of programming in a developing country context. Computer Science Education, 22 (13).

Ben-Ari, M., Ragonis, N., \& Ben-Bassat, Levy R. 2002. A vision of visualization in teaching object-oriented programming. Second Program Visualization Workshop. HornstrupCentret, Denmark, 84-90.

Boyle, T. Bradley,C Chalk, P, Jones, R \& Pickard, P. (2003). Using blended learning to improve student success rates in learning to program. Journal of Educational Media, $28,2-3$.

Gestwicki, P. and Jayaraman, B. (2002). Interactive visualization of Java programs. Proceedings of Symposia on Human Centric Computing Languages and Environments, 226-235

Kannusmäki, O., Moreno, A., Myller, N. \& Sutinen, E. (2004). What a novice wants: students using program visualization in distance programming course. Proceedings of the Third Program Visualization Workshop (PVW'04), 126-133.

Kolling, M., \& Rosenberg, J. (2000). Objects first with Java and BlueJ (seminar session). ACM SIGCSE Bulletin, 32 (1), 429.

Kolling, M., \& Rosenberg, J. (2001). Guidelines for teaching object orientation with Java. ACM SIGCSE Bulletin, 33(3), 33 - 36.

Kolling, M., Quig, B., Patterson, A., \& Rosenberg, J. (2003). The BlueJ system and its pedagogy. Computer Science Education, 13(4), 249 - 268.

Levy, R. B., Ben-Ari, M., \& Uronen, P.A. (2003). The Jeliot 2000 program animation system. Computers \& Education, 40 (1), 15-21.

Pears, A., Seidman, S Malmi, L Mannila, L Adams, E. Bennedsen, J., Devlin, M., \& Paterson, J. (2007). A survey of literature on the teaching of introductory programming. ACM SIGCSE Bulletin, 39 (4).

Rajala, T., Laakso, M.-J., Kaila, E. \& Salakoski, T. (2007). VILLE - A languageindependent program visualization tool. Proceedings of the Seventh Baltic Sea Conference on Computing Education Research, Koli National Park, Finland, November 15-18, 2007. Conferences in Research and Practice in Information Technology, Vol. 88, Australian Computer Society. Raymond Lister and Simon, Eds

Rajala, T., Laakso, M.-J., Kaila, E. \& Salakoski, T. (2008). Effectiveness of program visualization: a case study with the VILLE tool. Journal of Information Technology Education: Innovations in Practice, 7.

Sorva, J, Karavirta, V, \& Malmi, L. (2013). A review of generic program visualization systems for introductory programming education. ACM Transactions on Computing Education (TOCE), 13 (4).

Thramboulidis, Kleanthis C. (2013). A sequence of assignments to teach object-oriented programming: a constructivism design-first approach. Informatics in Education - An International Journal, 2 (1),103-112.

Wiedenbeck, Susan., Ramalingam, Vennila., \& Sarasamma, Suseela. Corritore, Cynthia. (1999). A comparison of the comprehension of object-oriented and procedural programs by novice programmers. Interacting with Computer, 11 (3). 